\title{
RANCANG BANGUN ALAT RAGUM DENGAN SISTEM KERJA OTOMATIS
}

\author{
EFRIZAL $^{1)}$ \& ASEP HIDAYAT ${ }^{2)}$ \\ Program Studi Teknik Mesin, Fakultas Teknik, Universitas Muhammadiyah Tangerang \\ Jl. Perintis Kemerdekaan I, No. 33, Cikokol, Tangerang, Banten 15118, Indonesia \\ Email: efrizal.arifin@gmail.com ${ }^{1)}$, asephidayat.ah72@gmail.com ${ }^{2)}$
}

\begin{abstract}
ABSTRAK
Alat Ragum (Catok) yang selama ini masih ada yang menggunakan system secara manual. Cara menjepit benda kerja yang dilakukan masih kurang efisien dan kurang sempurna dari segi waktu dan menggunakan tenaga. Tujuan dari pembuatan dan analisa alat ragum catok system otomatis ini ialah mengurangi dan menghemat waktu maupun tenaga yang terlalu banyak terbuang untuk system ragum manual. Dari hasil yang di peroleh dari analisa alat ini adalah tenaga dan waktu bias diminimalisir dan lebih efisien daripada menggunakan ragum catok secara manual. Hasil dari perancangan alat ragum catok ini adalah dilakukan dengan melakukan pengukuran lalu dibuat desain gambar 2D dan 3D alat ragum otomatis lalu membuat meja ragum sesuai ukuran. Dan system kerja alat ragum otomatis ini menggunakan remot control dan didukung dengan pemutus arus dengan penggerak mesin atau motor listrik sehingga membantu pengerjaan menjadi lebih efisien.
\end{abstract}

Kata Kunci: Perancangan, Alat, Ragum, Otomatis.

\section{PENDAHULUAN}

Dalam bidang industri proses mencekam atau menjepit pada suatu benda adalah proses penting yang dilakukan untuk mempermudah pada pekerjaan ketika sedang mengalami proses memotong, memahat, mengikir, mengelas dan sebagainya. Proses aktifitas alat bantu kerja tersebut pada umumnya memperhitungkan posisi kerja dan ukuran beda yang akan dijepit, terutama untuk para operator dapat mempermudah penggunaan alat tersebut ketika sedang melakukan proses pekerjaaan dan juga alat bantu ini berada ditingkat keamanan yang baik.

Perkembangan teknologi saat ini begitu pesat terutama pada dunia industri, sehingga alat-alat bantu perkakas menjadi kebutuhan pokok di berbagai macam industry bengkelbengkel besar sampai rumahan, artinya alatalat bantu perkakas dan teknologi merupakan penunjang dalam upaya meningkatkan produktifitas dan kenyamanan untuk berbagai jenis benda kerja dan sesuai dengan lingkungan kerja sekitar.
Membantu operator/ mahasiswa dalam melakukan pekerjaaan pada suatu benda kerja di Lab Teknik Mesin, UMT, maka Lab Teknik Mesin UMT membutuhkan alat bantu penjepit/ mencekam benda kerja yang sesuai dengan kebutuhan di area Lab Teknik Mesin UMT, konsep yang akan dibuat pada alat bantu tersebut ialah Ragum Catok dengan system kerja otomatis yaitu alat bantu untuk mencekam dan menjepit pada suatu benda kerja, dapat digunakan dengan mudah, dengan menekan tombol maka dynamo dan ulir akan memutar ragum catok dengan otomatis sehingga dapat mempermudah pekerjaanbagi operator dan mahasiswa.

\section{METODE PENELITIAN}

a. Desain Penelitian

Mengumpulkan data dan informasi sebagai bahan perencanaan alat Pada proses ini dilakukan dengan cara observasi untuk mengumpulkan data/informasi mengenai alat penjepit yang efektif. Setelah dilakukan pen- 
carian rancangan ditetapkan bahwa produk yang dibuat pada penelitian ini adalah Ragum Catok sebagai penjepit atau mencekam benda kerja otomatis dengan motor

\section{b. Bahan yang Digunakan}

Ragum catok adalah alat bantu untuk menjepit atau mencekam pada benda kerja semua ukuran dengan menggunakan motor sebagai penggerak otomatis.

Tabel 1 : Daftar Bahan Yang Digunakan

\begin{tabular}{|c|l|l|c|}
\hline No & \multicolumn{2}{|c|}{ Nama Bahan } & \multicolumn{2}{c|}{ Spesifikasi } & Ket \\
\hline 1 & Ragum & 3 Inch & Beli \\
\hline 2 & Dongkrak Elekrtik & Kapasitas Angkut 2 TON & Beli \\
\hline 3 & Besi Siku & $40 \times 40 \mathrm{~mm}$ & Beli \\
\hline 4 & Besi Plat Strip & $5 \times 30$ & Beli \\
\hline 5 & Kawat Las RB-26 & $2,6 \mathrm{~mm}$ & Beli \\
\hline 6 & Baut Mur & 8 Pcs & Beli \\
\hline 7 & Batu Gerinda Tipis WD Oren & 3 " & Beli \\
\hline 8 & Batu Gerinda Resibon & 3 " & Beli \\
\hline 9 & Kayu papan & $50 \times 50 \mathrm{~cm}$ & Beli \\
\hline
\end{tabular}

\section{c. Peralatan yang Digunakan}

Adapun peralatan yang digunakan untuk pembuatan alat dapat dilihat pada table sebagai berikut:

Tabel 2: Peralatan yang Digunakan

\begin{tabular}{|c|l|l|}
\hline No & \multicolumn{1}{|c|}{ Nama Alat } & \multicolumn{1}{c|}{ Fungsi } \\
\hline 1 & Mesin Las & Untuk menyatukan besi kerangka \\
\hline 2 & Gerinda Litrik & Untuk Memotong dan menghaluskan benda kerja \\
\hline 3 & Bor Listrik & Untuk Melubangi besi \\
\hline 5 & Penggaris Siku/ Meteran & Untuk mengukur yang ingin diukur \\
\hline 6 & multitester & Untuk mengukur kelistrikan \\
\hline 7 & Palu & Untuk memukul benda \\
\hline 8 & Kunci Ring, Pas Dan L & Untuk mengencangkan baut dan mur \\
\hline 9 & Sarung tangan & Untuk Keselamatan kerja \\
\hline 10 & Masker & Untuk Keselamatan kerja \\
\hline 11 & Kaca mata las & Untuk Keselamatan kerja \\
\hline 12 & Kuas & Untuk Mengecat Kerangka \\
\hline
\end{tabular}

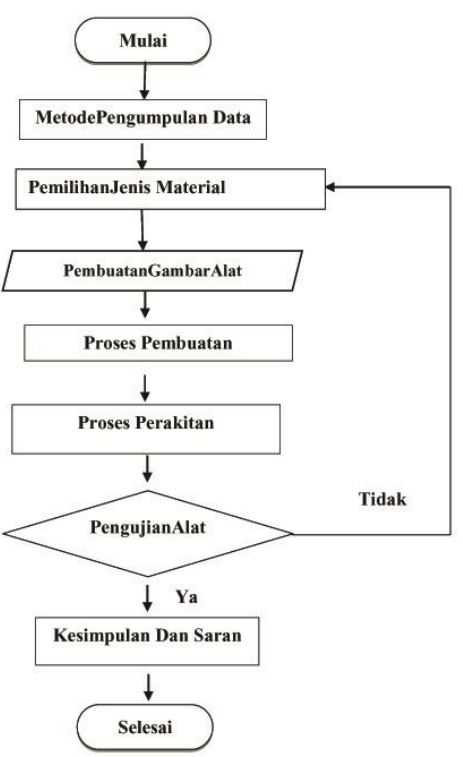

Gambar 1. Diagram Alir Proses Penelitian

\section{d. Persiapan Penelitian}

Sebelum penelitian dilakukan, terlebih dahulu mempersiapkan untuk melakukan penelitian yaitu merancang bentuk dan ukuran pada alat dan juga mempersiapkan bahan-bahan untuk penelitian.

\section{Pembuatan alat}

Berikut adalah langkah-langkah dalam proses pembuatan ragum otomatis:

a. Dirancang bentuk alat ragum otomatis

b. Di gambar atau desain bentuk alat ragum otomatis

c. Pemilihan bahan-bahan untuk pembuatan ragum otomatis

d. Melakukan pengukuran terhadap bahan-bahan yang akan digunakan sesuai ukuran yang telah direncanakan pada gambar alat

e. Pemotongan bahan sesuai dengan ukuran yang ditentukan

f. Dilakukan pengeboran untuk melubangi bagian-bagian rangka

g. Melakukan proses gerinda untuk pemotongan dan penghalusan pada bagian yang diinginkan

h. Melakukan proses pengelasan untuk menyusun rangka

i. Melakukan proses rangkaian terhadap rangka

j. Melakukan proses pengecatan untuk finishing juga agar tidak terhindar dari korosi

\section{Persiapan bahan}

Bahan yang digunakan untuk alat ragum adalah untuk semua ukuran dari panjang hingga tebal.

3. Prosedur penelitian

a. Disiapkan material dari benda kerja

b. Melakukan proses penjepitan pada material benda kerja

4. Parameter yang Diamati

a. Prinsip dari alat penjepit benda kerja Melakukan pengamatan cara kerja alat ragum otomatis

b. Keefektifan alat

Keefektifan alat dapat dilakukan dengan melihan proses penjepitan benda kerja ke ragum apakah adanya kendala 
ketika proses penjepitan benda tersebut.

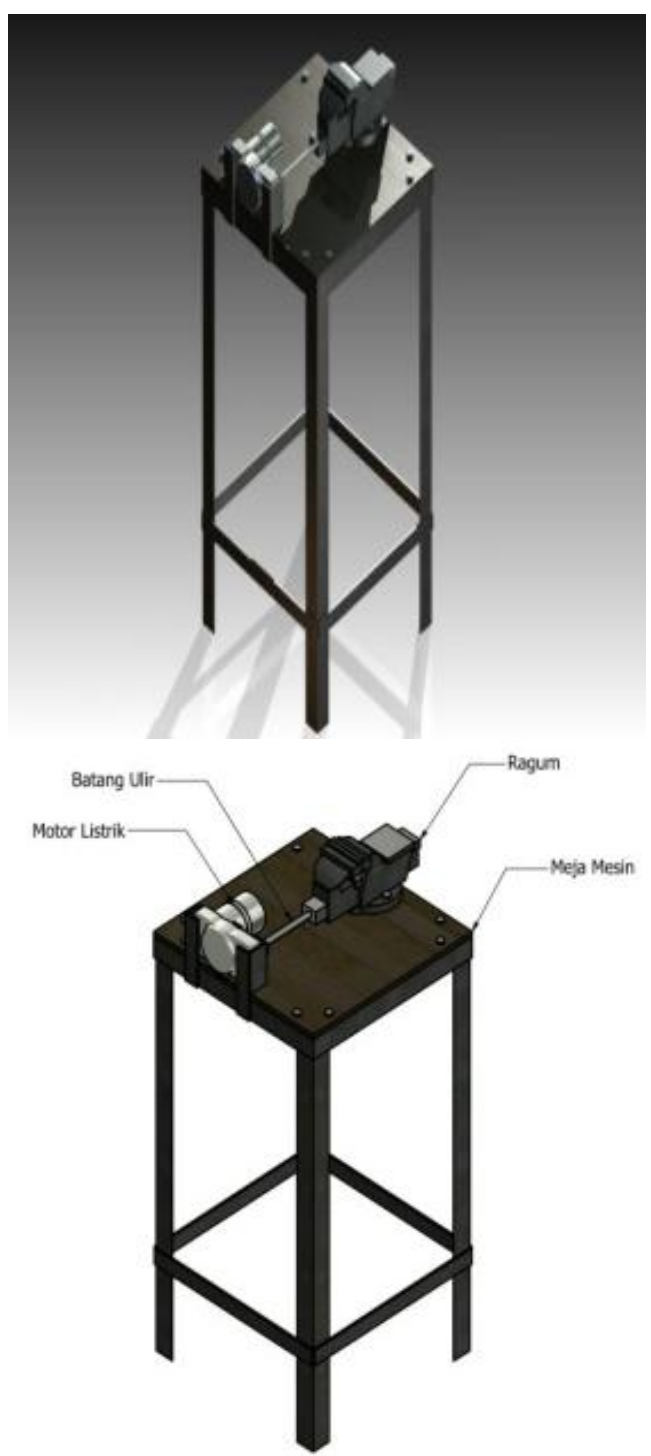

Gambar 2: Gambar Alat Ragum Otomatis.

Secara umum daya diartikan sebagai kemampuan yang dibutuhkan untuk melakukan kerja, yang dinyatakan dalam satuan Watt, ataupun Hp. Penentuan besar daya yang dibutuhkan perlu memperhatikan beberapa hal yang mempengaruhinya, diantaranya adalah gaya, torsi, dan berat yang bekerja pada mekanisme tersebut.

Berikut adalah rumus untuk mencari harga daya, gaya, torsi, kecepatan putar dan berat:

\section{a. Mencari harga daya $(P)$}

Berdasarkan putaran poros, daya dirumuskan (Khurmi dan Gupta,2005):

$P=\frac{2 \pi n T}{60}$
Dimana:

P : Daya (Watt)

$\mathrm{T}$ :Torsi (N.m)

$\mathrm{n}$ : Putaran poros (rpm)

b. Mencari harga Beban (W) Pada Poros Motor Listrik

Dari besarnya torsi yang bekerja pada poros motor listrik tersebut dapat dicari beban yang bekerja pada poros motor listrik tersebut. Menggunakan rumus (Khurmi dan Gupta,2005):

$\mathrm{W}=\frac{\mathrm{T}}{\mathrm{r}} \ldots$

Dimana :

$\mathrm{W}=\operatorname{beban}(N)$

$\mathrm{T}=$ torsi $(N . m)$

$\mathrm{r}=$ jari - jari poros motor $(\mathrm{mm})$

Perbandingan putaran transmisi (speed ratio), dinyatakan dalam notasi i :

Speed ratio :

$i=\frac{n_{1}}{n_{2}}=\frac{d_{2}}{d_{1}}=\frac{z_{2}}{z_{1}}$

Apabila:i $<1=$ transmisi roda gigi inkrisi dan $\mathrm{i}>1=$ transmisi roda gigi reduksi.

\section{HASIL ANALISA DAN PEMBA-} HASAN

a. Analisa

a. Untuk mengetahui nilai pada beban toris motor listrik DC dilakukan perhitungan sebagai berikut:

$$
\begin{aligned}
& \qquad P=\frac{2 \pi n T}{60} \\
& \text { Dimana: } \quad \mathrm{T}=\frac{60 . P}{2 \pi \cdot \mathrm{n}} \\
& \text { Maka: } \\
& =\frac{60 \times 120}{2 \times 3,14 \times 3000}=\frac{7.200}{18,840} \\
& \mathrm{~T}=0,3821 \\
& \mathrm{~T}=0,4(\mathrm{Nm})
\end{aligned}
$$

b. Sedangkan untuk mengetahui nilai pada beban motor listrik dari beban torsi yang bekerja pada motor listrik tersebut dapat dilakukan perhitungan dengan rumus sebagai berikut:

$$
\begin{array}{ll}
\text { Dimana: } & \mathrm{w}=\frac{\mathrm{T}}{\mathrm{r}} \\
\text { Maka: } & =\frac{0,4}{0,012}=33,33 \\
& \mathrm{w}=33(\mathrm{~N})
\end{array}
$$


Tabel 3: Nilai Spesifikasi Pada Motor.

\begin{tabular}{|l|l|}
\hline Daya (p) & 120 watt \\
\hline Torsi $(\mathrm{Nm})$ & $0,4 \mathrm{Nm}$ \\
\hline Putaranporos (n) & $3000 \mathrm{rpm}$ \\
\hline Jari-jariporos motor $(\mathrm{r})$ & $12 \mathrm{~mm}$ \\
\hline Beban $(\mathrm{w})$ & $33(\mathrm{~N})$ \\
\hline
\end{tabular}

c. Nilai Pada Roda Gigi Lurus

Untuk mengetahui perbandingan putaran pada roda gigi lurus dapat dihitung dengan rumus sebagai berikut:

Dimana: $\quad \mathrm{i}=\frac{\mathrm{n}_{1}}{\mathrm{n}_{2}}=\frac{\mathrm{d} 2}{\mathrm{~d} 1}=\frac{\mathrm{z} 2}{\mathrm{z} 1}$

Maka: $\quad \mathrm{i}=\frac{\mathrm{z} 2}{\mathrm{z} 1}=\frac{68}{7}$

$$
\mathrm{i}=9,7142
$$

Dimana: $\mathrm{i}=\frac{\mathrm{z} 2}{\mathrm{z} 1}$

$$
\mathrm{n} 2=\frac{\mathrm{n} 1}{\mathrm{i}}=\frac{3000}{9,7142}=308,8262
$$$$
\mathrm{n} 2=308,8262 \mathrm{rpm}
$$

Tabel 4: Nilai Perbandingan Roda Gigi Lurus

\begin{tabular}{|l|c|}
\hline Putaran poros yang penggerak (n1) & $3000 \mathrm{rpm}$ \\
\hline Putaan poros yang digerakan (n2) & $308,8 \mathrm{rpm}$ \\
\hline Junlah gigi penggerak (zl) & $7 \mathrm{buah}$ \\
\hline Jumlah gigi yang digerakan (z2) & $68 \mathrm{buah}$ \\
\hline Angka rasio (i) & 9,7142 \\
\hline
\end{tabular}

\section{b. Perhitungan Biaya Bahan Baku}

Biaya bahan baku adalah biaya pembelian bahan-bahan yang dibutuhkan dalam pembuatan alat ragum otomatis, adapun rincian biaya dari bahan baku dapat dijelaskan pada table berikut:

\begin{tabular}{|c|c|c|c|c|}
\hline NO & NAMA BAHAN & HARGA & QTY & JUMLAH \\
\hline 1 & RagumTekiro 3'Inch & $\operatorname{Rp} 500.000$ & 1 & $\operatorname{Rp} 500.000$ \\
\hline 2 & DongkrakElektrik & $\operatorname{Rp} 759.000$ & 1 & Rp 759.000 \\
\hline 3 & Besisiku & $\operatorname{Rp} 60.000$ & 3 & Rp 180.000 \\
\hline 4 & Besi Plat Strip 5/30 & $\operatorname{Rp} 40.000$ & 2 & Rp 80.000 \\
\hline 5 & Kawat Las RB-26 mm & Rp 130.000 & 1 & $\operatorname{Rp} 120.000$ \\
\hline 6 & BatuGerindaPotong & Rp 10.000 & 6 & Rp 20.000 \\
\hline 7 & BatuGerindaTebal & Rp 11.000 & 2 & Rp 22.000 \\
\hline 8 & Baut Mur 8,12 & $\operatorname{Rp} 8.000$ & 10 & $\operatorname{Rp} 80.000$ \\
\hline 9 & KayuPapan $40 \times 40$ & $\operatorname{Rp} 60.000$ & 1 & Rp 60.000 \\
\hline 10 & Cat Kayu\&Besi & Rp 10.000 & 2 & $\operatorname{Rp} 20.000$ \\
\hline 11 & Tiner & Rp 5.000 & 2 & Rp 10.000 \\
\hline 12 & Dempul & $\operatorname{Rp} 20.000$ & 1 & $\operatorname{Rp} 20.000$ \\
\hline 13 & OliGemuk & Rp 10.000 & 1 & Rp 10.000 \\
\hline \multicolumn{4}{|c|}{ Total Biaya } & $\operatorname{Rp~} 1,881,000$ \\
\hline
\end{tabular}

Tabel 5: Perhitungan Biaya Bahan Baku
Pada proses biaya pembuatan alat adalah seluruh biaya yang dikeluakan untuk membayar jasa operator pengeboran, pemotongan dan pengelasan, adapun rincian dari biaya pembuatan alat dapat dijelaskan pada table sebagaiberikut:

Tabel 6: Biaya Proses Pembuatan/ Pembentukan Bahan

\begin{tabular}{|c|c|c|c|}
\hline No & Pembuatan & Biaya Operator & Jumlah \\
\hline 1 & Pemotongan & Rp 200.000 & $\operatorname{Rp} 200.000$ \\
\hline 2 & Pengeboran & $\mathrm{Rp} 300.000$ & $\mathrm{Rp} 100.000$ \\
\hline 3 & Pengelasan & $\operatorname{Rp} 300.000$ & $\operatorname{Rp} 200.000$ \\
\hline \multicolumn{3}{|c|}{ Total Biaya } & $\operatorname{Rp} 800.000$ \\
\hline
\end{tabular}
Baku

Untuk seluruh total biaya yang dikeluarkan untuk perancangan alat ragum otomatis ini adalah sebagai berikut:

$$
\begin{aligned}
\text { Biaya total } & =\begin{array}{l}
\text { Biayabahanbaku }+ \text { Biaya } \\
\text { prose pembuatanalat }
\end{array} \\
& =1,881,000+80,000 \\
\text { Total } & =2,681,000
\end{aligned}
$$

\section{KESIMPULAN}

Dari hasil perancangan alat ragum otomatis dan system kerja ragum otomatis dapat disimpulkan sebagai berikut :

1. Tahap perancangan ragum otomatis ini dilakukan dengan awal melakukan pengukura-pengukuran lalu dibuat desain gambar 2D dan 3D alat ragum otomatis, lalu membuat meja ragum sesuai ukuran, ukuran meja ragum yaitu dengan tinggi $80 \mathrm{~cm}$ panjang/lebaryaitu $40 \times 40 \mathrm{~cm}$ dan kayu papan panjang/ lebar 40x40 $\mathrm{cm}$ dan tebal $5 \mathrm{~mm}$ kemudian dilakukan pelepasan tangkai dan ulir ragum lalu diganti dengan batang ulir yang sudah tersambung dengan dua buah roda gigi lurus dan motor listrik tipe DC dengan kapasitas 120 Watt.

2. Sistem kerja ragum otomatis ini menggunakan remot control dan didukung dengan pemutus arus, fungsi pemutus arus sendiri dipasang agar tidak terjadinya benturan antara ragum dan roda gigi, mengingat roda gigi tersebut terbuat dari bahan nylon yang mudah patah. 


\section{DAFTAR PUSTAKA}

Ansel C. Ugural. 2003. Mechanical Design: An Integrated Approach. McGrawHill inc, New York.

Khurmi, R. S., J. K. 2005. Machine Design. Eruasia Publising House, New Delhi.

Saito, S., \& Surdia, T. 2005. Pengetahuan Bahan Teknik. Pradnya Paramita, Jakarta.

Shigley, J. E. 2004. Standard Handbook of Machine Design, Califonia.

Sularso \& Kiyokatsu Suga. 1985. Dasar Perencanaan dan pemilihan Elemen Mesin, Pradnya Paramitha, Jakarta.
Ulrich, T, Karl. 2001. Perancangan dan Pengembangan Produk. Penerbit Salemba Empat. Jakarta.

Sumantri. 1989. Teori Kerja Bangku. Jakarta. Departemen pendidikan dan Kebudayaan Direktorat Jendral Pendidikan Tinggi Proyek Pengembangan.

Diditharyadi. 2012. Studi Pemilihan Motor $D C$ dan Kapasitasnya Pada Mobil Listrik. Universitas Sriwijaya, Jurusan Teknik Elektro Fakultas Teknik. 